
Ciência Jurídica da UNIVALI, Itajaí, v.14, n.2, $2^{\circ}$ quadrimestre de 2019. Disponível em: www.univali.br/direitoepolitica - ISSN 1980-7791

\title{
NEOLIBERALISMO E SOLIDARIEDADE: BREVES APONTAMENTOS DA TEORIA CRÍTICA DO DIREITO
}

\author{
NEOLIBERALISM AND SOLIDARITY: BRIEF NOTES ON THE CRITICAL THEORY OF
}

\author{
$L A W$
}

\author{
Alexandre Nogueira Pereira Neto ${ }^{1}$
}

\begin{abstract}
RESUMO
O presente trabalho tem como proposta geral analisar, dialeticamente, a política econômica neoliberal e o objetivo fundamental da solidariedade, consubstanciado no artigo 30, I, da Constituição da República Federativa do Brasil, de 1988, à luz da perspectiva da teoria crítica do direito. Em um primeiro momento, desenvolvem-se conceitos e características do neoliberalismo e seus efeitos no espaço social da política econômica brasileira. Posteriormente, analisa-se o fundamento constitucional da solidariedade e avaliam-se seus reflexos práticos, tendo em vista os impactos que esse fundamento sofre diante da interferência da economia neoliberal nas suas tentativas de consolidação. Por último, coteja-se a política econômica neoliberalizante com o fundamento da solidariedade sob o viés da teoria crítica do direito, com o fito de investigar a (im)possibilidade de convivência desses dois elementos quando estão presentes em um mesmo ambiente social.
\end{abstract}

PALAVRAS-CHAVE: Neoliberalismo; Solidariedade; Teoria crítica do direito.

\begin{abstract}
The present work has as a general proposal to analyze, deductively, the neoliberal economic policy and the fundamental objective of solidarity, embodied in article 3, I, of the Constitution of the Federative Republic of Brazil, 1988, in the light of the perspective of critical theory of law. At first, concepts and characteristics of neoliberalism and their effects on the social space of Brazilian economic policy are developed. Subsequently, the constitutional foundation of solidarity is analyzed and its practical reflections are evaluated, considering the impacts that this foundation suffers in the face of the interference of the neoliberal economy in its attempts to consolidate. Finally, neoliberalizing economic policy is compared with the foundation of solidarity under the bias of the critical theory of law, with the

\footnotetext{
1 Mestre em Direito, na linha de pesquisa Estado e Constituição, com área de concentração em Direitos Sociais. Programa de Pós-Graduação em Direito da Faculdade de Direito da Universidade Federal de Pelotas (UFPEL). Especialista em Direito Processual Civil pelo Complexo de Ensino Superior de Santa Catarina (CESUSC). Graduado em Direito pelo CESUSC. Advogado. Pelotas, RS, Brasil. E-mail: alexandrenpn@gmail.com.
} 
PEREIRA NETO, Alexandre Nogueira. Neoliberalismo e Solidariedade: breves apontamentos da Teoria Crítica do Direito. Revista Eletrônica Direito e Política, Programa de Pós-Graduação Stricto Sensu em Ciência Jurídica da UNIVALI, Itajaí, v.14, n.2, $2^{\circ}$ quadrimestre de 2019. Disponível em: www.univali.br/direitoepolitica - ISSN 1980-7791

purpose of investigating the (im) possibility of coexistence of these two elements when they are present in the same social environment.

KEYWORDS: Neoliberalism; Solidarity; Critical Theory of Law.

\section{INTRODUÇÃO}

O processo de transição democrática, no Brasil, começou em meados de 1985, após o período de 20 anos de ditadura no País. Logo depois, com o advento da Constituição da República Federativa do Brasil, de 1988, foi implantado um ambiente de estabilidade institucional. Os avanços democráticos conquistados, tais como os direitos sociais, são de demasiada importância para o progresso de um Estado Social (Welfare State), em permanente construção e aprimoramento.

Diante disso, foram inseridos, por meio do constituinte, alguns objetivos fundamentais para que nortear as ações jurídico-políticas da República Federativa do Brasil. Um desses objetivos fundamentais é a solidariedade, que tem previsão expressa no artigo 30, I, da Carta Magna. A ideia central desse comando constitucional é de que deve haver um pacto de responsabilidade recíproca entre o Estado e a sociedade, no que toca às relações sociais, principalmente. Isto é, o Estado, por meio de ações públicas, deve promover políticas, de viés social, com o intuito de amenizar os desequilíbrios sociais que convivem, ainda que de modo conflituoso, em determinado espaço.

Simultaneamente, em meio à era da globalização, promove-se, desenfreadamente, uma política econômica que, em vez de proporcionar estabilidade nas relações sociais, postula graves entraves na qualidade e na satisfação de direitos, sobretudo, sociais. Essa política econômica denomina-se de neoliberalismo. O neoliberalismo é uma linha econômica que tem como objetivo operacionalizar, sem o controle / a intervenção do Estado - em princípio, o desenvolvimento político, econômico e social de um País. O Estado, portanto, nesse prisma, tem sua área de atuação diminuída, fazendo com que privilegiados grupos empresariais, de vultoso poder financeiro, orquestrem os rumos de uma nação. 
PEREIRA NETO, Alexandre Nogueira. Neoliberalismo e Solidariedade: breves apontamentos da Teoria Crítica do Direito. Revista Eletrônica Direito e Política, Programa de Pós-Graduação Stricto Sensu em Ciência Jurídica da UNIVALI, Itajaí, v.14, n.2, $2^{\circ}$ quadrimestre de 2019. Disponível em: www.univali.br/direitoepolitica - ISSN 1980-7791

Diante dos elementos expostos - solidariedade e neoliberalismo - surge a problemática da pesquisa: podem esses elementos conviverem harmonicamente em um mesmo espaço social?

O objetivo geral deste trabalho se dá no sentido de promover a discussão entre o neoliberalismo e a solidariedade para verificar o que significa cada um desses elementos e desenvolver uma perspectiva crítica sobre tal temática. Em relação aos objetivos específicos, analisar o conceito, significados e efeitos do neoliberalismo como proposta de política econômica; avaliar o instituto constitucional da solidariedade, seja em seu aspecto de parâmetro e de diretriz do Estado, seja em seu aspecto coletivo no que diz respeito aos atores sociais; examinar a teoria crítica do direito como uma ferramenta fundamental de verificação da manutenção do status quo dominante que o neoliberalismo promove apontando, por fim, alguns elementos alternativos de resistência.

Dessa forma, o presente trabalho procura apresentar a (im)possibilidade de consonância desses preceitos - neoliberalismo e solidariedade - no âmbito da política brasileira, utilizando a metodologia dialética - por meio de pesquisa bibliográfica - sob a perspectiva da teoria crítica do direito. É esse o ponto central do trabalho: confrontar a política econômica neoliberal, que se fortalece no plano da política econômica brasileira, com o objetivo fundamental da República, que é a solidariedade, e analisar, dialeticamente, a possível viabilidade de convivência desses parâmetros.

\section{NEOLIBERALISMO}

Preambularmente, é primordial definir, de maneira geral, o significado de neoliberalismo. Registra-se que essa aferição será delineada conforme o entendimento do autor sobre esse assunto, na medida em que se trata de uma temática em que há divergência no campo científico. Tal sentido, portanto, norteará a visão que se dará à política econômica neoliberal no deslinde do trabalho. 
PEREIRA NETO, Alexandre Nogueira. Neoliberalismo e Solidariedade: breves apontamentos da Teoria Crítica do Direito. Revista Eletrônica Direito e Política, Programa de Pós-Graduação Stricto Sensu em Ciência Jurídica da UNIVALI, Itajaí, v.14, n.2, $2^{\circ}$ quadrimestre de 2019. Disponível em: www.univali.br/direitoepolitica - ISSN 1980-7791

Feita a devida ponderação, o neoliberalismo, dessa forma, "consiste em um conjunto de políticas e processos que permitem a um número relativamente pequeno de interesses particulares controlar a maior parte possível da vida social com o objetivo de maximizar seus benefícios individuais". ${ }^{2}$ Isto é, essa política econômica propõe o monopólio de decisões a um grupo específico de pessoas sobre diversas demandas, inclusive sociais, o que acarreta a supressão de participação da sociedade em matérias de extrema importância.

O que se nota, portanto, é que por trás da estrutura estatal há atores que atuam no sentido de dirigir esse órgão com o objetivo de estabelecer suas premissas empresariais. Desvirtua-se, nesse sentido, o papel do Estado, que deve garantir e promover o desenvolvimento humano de determinado espaço social, para atender aos anseios de seletas corporações. Essas pretensões, indubitavelmente, terão conotações corporativas e não republicanas. ${ }^{3}$

É o que preconiza Dardot e Laval:

[...] o sistema neoliberal é instaurado por forças e poderes que se apoiam uns aos outros em nível nacional e internacional. Oligarquias burocráticas e políticas, multinacionais, atores financeiros e grandes organismos econômicos internacionais formam uma coalizão de poderes concretos que exercem uma certa função política em escala mundial. Hoje, a relação de forças pende inegavelmente a favor desse bloco oligárquico. ${ }^{4}$

O Estado, agindo dessa forma, atua de modo antidemocrático, pois o que se pretende nessas negociações não é atingir o bem comum e o aprimoramento dos direitos e garantias constitucionais mas, sim, atender a escusos interesses que não

\footnotetext{
2 CHOMSKY, Noam. O lucro ou as pessoas. Seven Stories Press: NY, 1999. p. 12.

3 O verdadeiro motor da história continua a ser o poder do capital, que subordina o Estado e a sociedade, colocando-os a serviço de sua acumulação cega. DARDOT, Pierre; LAVAL, Christian. A nova razão do mundo: ensaios sobre a sociedade neoliberal. 1 ed. São Paulo: Boitempo, 2016. p. 23.

4 DARDOT, Pierre; LAVAL, Christian. A nova razão do mundo: ensaios sobre a sociedade neoliberal. p. 8.
} 
PEREIRA NETO, Alexandre Nogueira. Neoliberalismo e Solidariedade: breves apontamentos da Teoria Crítica do Direito. Revista Eletrônica Direito e Política, Programa de Pós-Graduação Stricto Sensu em Ciência Jurídica da UNIVALI, Itajaí, v.14, n.2, 20 quadrimestre de 2019. Disponível em: www.univali.br/direitoepolitica - ISSN 1980-7791

se coadunam com o axioma de Estado Democrático de Direito ${ }^{5}$ e, portanto, da solidariedade.

Por isso, essa "subalternidade da política à economia ajuda a explicar a atual crise de legitimidade dos órgãos eletivos, aos quais compete, por meio de um discurso falacioso e, por vezes, ridículo, editar legislações francamente antissociais, mas que beneficiam o seu senhor, o mercado". ${ }^{6}$

Corroborando com a ideia de Valim, o modelo econômico-político contemporâneo é a assertiva de que o tratamento que se dá aos direitos sociais ${ }^{7}$ é, evidentemente, um desmando para que sejam mantidos os intocáveis privilégios das elites financeiras ${ }^{8}$, promovendo, assim, a ineficiência da implementação de políticas públicas e, consequentemente, aumentando o corte dos gastos sociais ${ }^{9}$. Assim, o neoliberalismo, que protege a autonomia do mercado e reduz a intervenção estatal sobre a economia, inverte a lógica de um Estado Social, que, por meio de seus programas sociais, busca atender as pessoas hipossuficientes e, por consequência, possibilita o acesso aos direitos e às garantias previstas na Constituição Cidadã.

\footnotetext{
5 É o que promove o preâmbulo da Carta Magna de 1988: "nós, representantes do povo brasileiro, reunidos em Assembleia Nacional Constituinte para instituir um Estado Democrático, destinado a assegurar o exercício dos direitos sociais e individuais, a liberdade, a segurança, o bem-estar, o desenvolvimento, a igualdade e a justiça como valores supremos de uma sociedade fraterna, pluralista e sem preconceitos, fundada na harmonia social e comprometida, na ordem interna e internacional, com a solução pacífica das controvérsias, promulgamos, sob a proteção de Deus, a seguinte Constituição da República Federativa do Brasil". BRASIL. Constituição da República Federativa do Brasil de 5 de outubro de 1988. Disponível em: <http://www.planalto.gov.br/ccivil_03/constituicao/constituicaocompilado.htm>. Acesso em: 31 out. 2018.

6 VALIM, Rafael. Estado de Exceção: a forma jurídica do neoliberalismo. São Paulo: Contracorrente, 2017. p. 29.

7 O artigo $6^{\circ}$ da Constituição da República Federativa do Brasil de 1988 estabelece que "são direitos sociais a educação, a saúde, a alimentação, o trabalho, a moradia, o transporte, o lazer, a segurança, a previdência social, a proteção à maternidade e à infância, a assistência aos desamparados, na forma desta Constituição". BRASIL. Constituição da República Federativa do Brasil de 5 de outubro de 1988. Disponível em: <http://www.planalto.gov.br/ccivil_03/constituicao/constituicaocompilado.htm>. Acesso em: 31 out. 2018.

8 Segundo estudo lançado pela Oxfam em 16 de janeiro de 2017, prévio ao Fórum Econômico Mundial, o patrimônio de apenas oito homens é igual ao da metade mais pobre do mundo e $1 \%$ da humanidade controla uma riqueza equivalente a dos demais $99 \%$. VALIM, Rafael. Estado de Exceção: a forma jurídica do neoliberalismo. p. 31.

${ }^{9}$ A pressão especulativa dos investidores privados sobre o mercado da dívida pública e a pressão das agências de classificação de risco, sem falar da impossibilidade de desvalorização, são todos aspectos de uma mesma lógica disciplinadora com uma temível eficácia para rebaixar os salários e diminuir a proteção social. DARDOT, Pierre; LAVAL, Christian. A nova razão do mundo: ensaios sobre a sociedade neoliberal. p. 29.
} 
PEREIRA NETO, Alexandre Nogueira. Neoliberalismo e Solidariedade: breves apontamentos da Teoria Crítica do Direito. Revista Eletrônica Direito e Política, Programa de Pós-Graduação Stricto Sensu em Ciência Jurídica da UNIVALI, Itajaí, v.14, n.2, 20 quadrimestre de 2019. Disponível em: www.univali.br/direitoepolitica - ISSN 1980-7791

A política econômica neoliberal fomenta, na verdade, a acumulação de riqueza, tornando, portanto, grandes setores empresariais cada vez mais poderosos potencializando, demasiadamente, os desequilíbrios sociais e aumentando, assim, a miséria. Foi o que ocorreu, por exemplo, em países que adotaram esses vieses econômicos e, diante disso, tiveram decorrências graves, que foram "um enorme crescimento da desigualdade econômica e social, um aumento marcante da pobreza absoluta entre as nações e povos mais atrasados do mundo, um meio ambiente global catastrófico, uma economia global instável e uma bonança sem precedente para os ricos". ${ }^{10}$

Observa-se que essa forma de política econômica não exalta a promoção de políticas sociais e de distribuição de renda, mas sim serve a interesses privados transformando direitos de cunho social em mercadorias, pois quem decide os rumos da humanidade "é o chamado "mercado", em nome de uma elite invisível e ilocalizável". 11

De outro lado, "o neoliberalismo não é apenas uma ideologia, um tipo de política econômica. É um sistema normativo que ampliou sua influência ao mundo inteiro, estendendo a lógica do capital a todas as relações sociais e a todas as esferas da vida". ${ }^{12}$ O neoliberalismo não produz, pois, apenas efeitos no campo econômico de uma área social, mas, também, em aspectos inter-relacionais. ${ }^{13} \mathrm{O}$ comportamento humano, diante das interferências que recebe dessa imposição econômica, sofre alteração, sobretudo sob o prisma da solidariedade, na medida em que a lógica dessa corrente é da concorrência desenfreada entre os sujeitos que convivem em sociedade. ${ }^{14}$

${ }^{10}$ CHOMSKY, Noam. O lucro ou as pessoas. p. 13.

11 VALIM, Rafael. Estado de Exceção: a forma jurídica do neoliberalismo. p. 33.

12 DARDOT, Pierre; LAVAL, Christian. A nova razão do mundo: ensaios sobre a sociedade neoliberal. p. 7.

${ }^{13}$ A sociedade neoliberal em que vivemos é fruto de um processo histórico que não foi integralmente programado por seus pioneiros; os elementos que a compõem reuniram-se pouco a pouco, interagindo uns com os outros, fortalecendo uns aos outros. DARDOT, Pierre; LAVAL, Christian. A nova razão do mundo: ensaios sobre a sociedade neoliberal. p. 24.

${ }^{14}$ A crise mundial é uma crise geral da "governabilidade neoliberal", isto é, de um modo de governo das economias e das sociedades baseado na generalização do mercado e da concorrência. DARDOT, Pierre; LAVAL, Christian. A nova razão do mundo: ensaios sobre a sociedade neoliberal. $p$. 27. 
PEREIRA NETO, Alexandre Nogueira. Neoliberalismo e Solidariedade: breves apontamentos da Teoria Crítica do Direito. Revista Eletrônica Direito e Política, Programa de Pós-Graduação Stricto Sensu em Ciência Jurídica da UNIVALI, Itajaí, v.14, n.2, $2^{\circ}$ quadrimestre de 2019. Disponível em: www.univali.br/direitoepolitica - ISSN 1980-7791

Ou seja:

[...] trata-se, na verdade, de produzir uma relação do sujeito individual com ele mesmo que seja homóloga à relação do capital com ele mesmo ou, mais precisamente, uma relação do sujeito com ele mesmo como um 'capital humano' que deve crescer indefinidamente, isto é, um valor que deve valorizar-se cada vez mais. ${ }^{15}$

Assim, "não podemos ignorar as mutações subjetivas provocadas pelo neoliberalismo que operam no sentido do egoísmo social, da negação da solidariedade e da redistribuição". ${ }^{16}$

O neoliberalismo, "antes de ser uma ideologia ou uma política econômica, é em primeiro lugar e fundamentalmente uma racionalidade e, como tal, tende a estruturar e organizar não apenas a ação dos governantes, mas até a própria conduta dos governados". ${ }^{17}$ Nesse ponto de vista, Dardot e Laval traduzem que:

[...] o neoliberalismo não destrói apenas regras, instituições, direitos. Ele também produz certos tipos de relações sociais, certas maneiras de viver, certas subjetividades. Em outras palavras, com o neoliberalismo o que está em jogo é nada mais nada menos que a forma da nossa existência, isto é, a forma como somos levados a nos comportar, a nos relacionar com os outros e com nós mesmos. O neoliberalismo define certa norma de vida nas sociedades ocidentais e, para além dele, em todas as sociedades que as segue no caminho da "modernidade". Essa norma impõe a cada um de nós que vivamos num universo de competição generalizada, intima os assalariados e as populações a entrar em luta econômica uns contra os outros, ordena as relações sociais segundo o modelo de mercado, obriga a justificar desigualdades sociais cada vez mais profundas, muda até o indivíduo, que é instado a conceber a si mesmo e a comportar-se como uma empresa. ${ }^{18}$

15 DARDOT, Pierre; LAVAL, Christian. A nova razão do mundo: ensaios sobre a sociedade neoliberal. p. 31.

16 DARDOT, Pierre; LAVAL, Christian. A nova razão do mundo: ensaios sobre a sociedade neoliberal. p. 9.

17 DARDOT, Pierre; LAVAL, Christian. A nova razão do mundo: ensaios sobre a sociedade neoliberal. p. 17.

18 DARDOT, Pierre; LAVAL, Christian. A nova razão do mundo: ensaios sobre a sociedade neoliberal. p. 16. 
PEREIRA NETO, Alexandre Nogueira. Neoliberalismo e Solidariedade: breves apontamentos da Teoria Crítica do Direito. Revista Eletrônica Direito e Política, Programa de Pós-Graduação Stricto Sensu em Ciência Jurídica da UNIVALI, Itajaí, v.14, n.2, 20 quadrimestre de 2019. Disponível em: www.univali.br/direitoepolitica - ISSN 1980-7791

Depreende-se, portanto, que o "neoliberalismo emprega técnicas de poder inéditas sobre as condutas e as subjetividades. Ele não pode ser reduzido à expansão espontânea da esfera mercantil e do campo da acumulação do capital". ${ }^{19}$ É preciso, por isso, oxigenar a concepção que se tinha, puramente monetária, da política econômica neoliberal. Ela fomenta, inevitavelmente, outros sentidos da seara social. Os atores sociais são, diariamente, motivados a concorrerem entre si e essas incitações alimentam as subjetividades individuais. Valores que as sociedades mecânicas ${ }^{20}$ proporcionavam são brutalmente transgredidos, em razão do ideário econômico neoliberal, uma vez que o critério de troca foi substituído pelo raciocínio capitalista. Por conseguinte, mais uma vez é imperioso trazer à colação as contribuições de Dardot e Laval sobre essas outras repercussões que produzem o neoliberalismo, a mando do capital, na vida pós-moderna ${ }^{21}$ :

[...] continuar a acreditar que o neoliberalismo não passa de uma "ideologia", uma "crença", um "estado de espírito" que os fatos objetivos, devidamente observados, bastariam para dissolver, como o sol dissipa a névoa matinal, é travar o combate errado e condenar-se à impotência. O neoliberalismo é um sistema de normas que hoje estão profundamente inscritas nas práticas governamentais, nas políticas institucionais, nos estilos gerenciais. Além disso, devemos deixar claro que esse sistema é tanto mais "resiliente" quando excede em muito a esfera mercantil e financeira em que reina o capital. Ele estende a lógica do mercado muito além das fronteiras estritas do mercado, em especial produzindo uma subjetividade "contábil" pela criação da concorrência sistemática entre os indivíduos. ${ }^{22}$

Outro fator que ocorre, em tempos neoliberais, é o total descomprometimento com a política e com a cidadania, visto que essa sensação de disputa criada nas relações sociais pelo neoliberalismo fabrica um ambiente de cada um por si. Consequência

19 DARDOT, Pierre; LAVAL, Christian. A nova razão do mundo: ensaios sobre a sociedade neoliberal. p. 21.

20 Sociedade mecânica é uma expressão que foi difundida pelo filósofo francês David Émile Durkheim. As sociedades mecânicas preconizavam preposições de sociedades simples e a sua compreensão econômica não necessariamente objetivava o lucro, e sim a troca de habilidades, isto é, havia uma espécie de econômica solidária.

21 Importante registrar que a expressão pós-modernidade é fonte de debate no meio acadêmico, porque muitos estudiosos dessa temática entendem que há problemas terminológicos nesse termo. Contudo, essas objeções não serão problematizadas, neste estudo, pois não é o seu objetivo.

22 DARDOT, Pierre; LAVAL, Christian. A nova razão do mundo: ensaios sobre a sociedade neoliberal. p. 30. 
PEREIRA NETO, Alexandre Nogueira. Neoliberalismo e Solidariedade: breves apontamentos da Teoria Crítica do Direito. Revista Eletrônica Direito e Política, Programa de Pós-Graduação Stricto Sensu em Ciência Jurídica da UNIVALI, Itajaí, v.14, n.2, $2^{\circ}$ quadrimestre de 2019. Disponível em: www.univali.br/direitoepolitica - ISSN 1980-7791

disso, é a "abstenção eleitoral, dessindicalização, racismo, tudo parece conduzir à destruição das condições do coletivo e, por consequência, ao enfraquecimento da capacidade de agir contra o neoliberalismo". ${ }^{23}$

Esses fatores influenciam na organização social da população, visto que é impreterível atinar como os problemas sociais devem ser detectados e suas possíveis soluções. Enfim, a participação do povo nas decisões populares é condição necessária para que um Estado seja democrático, senão "uma democracia sem povo, a serviço do mercado, e que, ao menor sinal de insurgência contra a sua atual conformação, é tomada por medidas autoritárias". ${ }^{24}$

Pode-se perceber que a política econômica neoliberal proporciona o aumento da concentração de riqueza ocasionando, assim, alarmantes desigualdades sociais, promovendo o sentimento de individualismo entre os cidadãos que são afetados pelo seu reflexo, deteriorando, então, a solidariedade, afastando o interesse da população em participar das decisões políticas e dos rumos do País, reduzindo a possibilidade do acesso aos direitos sociais, na medida em que esses direitos são transformados em privilégios e em mercadorias, e não tratados como direitos essenciais à manutenção da vida. O neoliberalismo, assenta, portanto, a transformação da "democracia liberal em uma retórica vazia, sem correspondência com a realidade. E é exatamente neste antagonismo, cada vez mais claro, entre a ordem democrática e o neoliberalismo que irrompem os estados de exceção."25

Então, diante das considerações acima expostas, notar-se-á, no item seguinte, que o objetivo fundamental da República da solidariedade sofrerá graves fissuras, tendo em vista a influência das elites financeiras e de grandes grupos empresariais nas deliberações econômicas, políticas, sociais e jurídicas do Estado, pois, a partir dessas negociações, o que se pretende é o lucro, e não o desenvolvimento humano e social de determinado ambiente coletivo.

23 DARDOT, Pierre; LAVAL, Christian. A nova razão do mundo: ensaios sobre a sociedade neoliberal. p. 9.

${ }^{24}$ VALIM, Rafael. Estado de Exceção: a forma jurídica do neoliberalismo. p. 30.

25 VALIM, Rafael. Estado de Exceção: a forma jurídica do neoliberalismo. p. 33. 
PEREIRA NETO, Alexandre Nogueira. Neoliberalismo e Solidariedade: breves apontamentos da Teoria Crítica do Direito. Revista Eletrônica Direito e Política, Programa de Pós-Graduação Stricto Sensu em Ciência Jurídica da UNIVALI, Itajaí, v.14, n.2, $2^{\circ}$ quadrimestre de 2019. Disponível em: www.univali.br/direitoepolitica - ISSN 1980-7791

\section{SOLIDARIEDADE}

Sobre o termo solidariedade, Comparato assim se manifestou:

O substantivo solidum, em latim, significa a totalidade de uma soma; solidus tem o sentido de inteiro ou completo. A solidariedade não diz respeito, portanto, a uma unidade isolada, nem a uma proporção entre duas ou mais unidades, mas à relação de todas as partes de um todo, entre si e cada uma perante o conjunto de todas elas. São de cunho solidário não só o conjunto das relações interindividuais dos cidadãos na sociedade política, e dos povos na cena internacional, mas também a relação do Estado com qualquer cidadão ou grupo de cidadãos, ou da Organização das Nações Unidas com qualquer de seus membros. ${ }^{26}$

A ideia de criar elementos para servir de parâmetros no sentido da construção de uma nação tem sua gênese, ${ }^{27}$ também, nas desastrosas batalhas humanas que resultaram em barbáries e graves violações dos direitos humanos. ${ }^{28}$ Fez-se necessário, portanto, criar elementos de normatividade, consubstanciados em premissas constitucionais, para evitar outros grandes conflitos e, sobretudo, para limitar a atuação do poder.

Diante disso, após o período de exceção, iniciado por meio do golpe militar de 1964, a democracia foi restabelecida, no País, em 1988, com a promulgação da Constituição da República Federativa do Brasil consolidando, assim, o Estado Democrático de Direito.

O constituinte, à vista disso, fixou enunciados que devem ser levados em consideração em todas as decisões políticas, administrativas, jurídicas e econômicas e, por isso, enumerou alguns objetivos fundamentais que servem de

26 COMPARATO, Fábio Konder. Ética: direito, moral e religião no mundo moderno. 3 ed. São Paulo: Companhia das Letras, 2016. p. 581.

27 A fixação desse ponto de partida é um dado de fundamental importância, pois as grandes transformações do Estado e os grandes debates sobre ele, nos dois últimos séculos, têm sido determinados pela crença naqueles postulados, podendo se concluir que os sistemas políticos do século XIX e da primeira metade do século XX não foram mais do que tentativas de realizar as aspirações do século XVIII. DALLARI, Dalmo de Abreu. Elementos de teoria geral do estado. 27 ed. São Paulo: Saraiva, 2007. p. 54.

28 Nesse sentido, "a ideia moderna de um Estado Democrático tem suas raízes no século XVIII, implicando a afirmação de certos valores fundamentais da pessoa humana, bem como a exigência de organização e funcionamento do Estado tendo em vista a proteção daqueles valores". DALLARI, Dalmo de Abreu. Elementos de teoria geral do estado. p. 54. 
PEREIRA NETO, Alexandre Nogueira. Neoliberalismo e Solidariedade: breves apontamentos da Teoria Crítica do Direito. Revista Eletrônica Direito e Política, Programa de Pós-Graduação Stricto Sensu em Ciência Jurídica da UNIVALI, Itajaí, v.14, n.2, $2^{\circ}$ quadrimestre de 2019. Disponível em: www.univali.br/direitoepolitica - ISSN 1980-7791

guia para a construção de uma sociedade mais justa, igualitária e solidária. Essas direções foram positivadas na norma maior de nossa estrutura jurídica, fundamentalmente, no artigo 30, I, da Constituição da República Federativa do Brasil de 1988, contendo a seguinte redação:

Constituem objetivos fundamentais da República Federativa do Brasil: I - construir uma sociedade livre, justa e solidária; II - garantir o desenvolvimento nacional; III - erradicar a pobreza e a marginalização e reduzir as desigualdades sociais e regionais; IV - promover o bem de todos, sem preconceitos de origem, raça, sexo, cor, idade e quaisquer outras formas de discriminação. ${ }^{29}$

Nesse sentido, a interpretação que se dá é de que a pretensão do legislador, quando da positivação do objetivo fundamental da solidariedade, projeta a construção de uma sociedade que promova políticas públicas, inclusive educacionais, para que as relações sociais não sejam balizadas pelo critério da concorrência entre os indivíduos, mas sim que proporcionem um ambiente social em que o diálogo, a ética, o auxílio e, sobretudo, a solidariedade sejam premissas primárias.

Em uma sociedade cujos princípios solidários sejam trabalhados e promovidos, principalmente por meio de ações políticas, a consciência coletiva é difundida e, quiçá, exercida plenamente. O ser humano é um ser social e, em função disso, é imprescindível o convívio com os demais atores que compõem a sociedade em que vive. Até porque:

[...] o homem não sobrevive sozinho, ele se encontra na companhia do outro e numa comunidade em geral organizada, por isso, não é um ser só, mas social (comunitário). Ele é instruído para viver no mundo por meio da ajuda do outro, em face disto quem não precisa da sociedade é Deus (ou deuses) ou animal. A conexão entre solidariedade e pessoa está na relação eu e outro. ${ }^{30}$

29 BRASIL. Constituição da República Federativa do Brasil de 5 de outubro de 1988. Disponível em: <http://www.planalto.gov.br/ccivil_03/constituicao/constituicaocompilado.htm>. Acesso em: 31 out. 2018.

30 MORAIS, José Luiz Bolzan de; MASSAÚ, Guilherme Camargo. A solidariedade como elemento constitutivo da res pública. Pensar, Fortaleza, v. 16, n. 1, p. 166, jan./jun. 2011. 
PEREIRA NETO, Alexandre Nogueira. Neoliberalismo e Solidariedade: breves apontamentos da Teoria Crítica do Direito. Revista Eletrônica Direito e Política, Programa de Pós-Graduação Stricto Sensu em Ciência Jurídica da UNIVALI, Itajaí, v.14, n.2, 20 quadrimestre de 2019. Disponível em: www.univali.br/direitoepolitica - ISSN 1980-7791

Percebe-se que a ideia da economia neoliberal, consoante todos os elementos trazidos no item dois deste artigo, advoga, justamente, para o confronto e a disputa social. Ou seja, quanto maior a ausência de diálogo em um espaço social, maior será o distanciamento da população nas demandas políticas, o que acarreta improváveis mobilizações no sentido de ruptura do programa econômico imposto, perpetuando, assim, o comando de administração de um país a classes que não têm o objetivo de equalizar, a título de exemplo, desarmonias sociais. O controle social, por parte da população, dos rumos que tomam o País, é indispensável, mormente, para a aferição da qualidade democrática de um Estado. Podemos afirmar, portanto, que a política econômica neoliberal diminui a qualidade democrática de um País, tendo em vista que suas práticas afastam os atores sociais do campo político, do espaço social e, principalmente, de valores solidários, porque são instigados a olhar o outro como rival, e não como um elemento que constitui a sua própria natureza. Perde-se, nesse sentido, a afeição da responsabilidade social, ${ }^{31}$ na medida em que "a unidade maior a englobar todos os indivíduos e grupos sociais, essa finalidade última, eticamente falando, é propiciar o aperfeiçoamento constante de todos os seus componentes, segundo as qualidades próprias da pessoa humana". ${ }^{32}$

Uma sociedade solidária ${ }^{33}$ necessita de cooperação entre os atores sociais. Que o outro seja visto como um aliado e não como um inimigo. Assim sendo, é importante registrar a notável reflexão de Comparato sobre a importância da consolidação de preceitos solidários:

[...] ela é o fecho de abóboda do sistema de princípios éticos, pois complementa e aperfeiçoa a liberdade, a igualdade e a segurança. Enquanto a liberdade e a igualdade põem as pessoas umas diante das outras, a solidariedade reúne, todas,

${ }^{31} \mathrm{O}$ vínculo de solidariedade entre todos os que compõem politicamente o mesmo povo de um Estado determinado está na origem do conjunto dos direitos fundamentais de natureza econômica, social e cultural. COMPARATO, Fábio Konder. Ética: direito, moral e religião no mundo moderno. p. 583.

32 COMPARATO, Fábio Konder. Ética: direito, moral e religião no mundo moderno. p. 583.

33 A solidariedade atua em três dimensões complementares: nacional, internacional e intergeracional. A cada uma delas corresponde um conjunto específico de direitos humanos, os quais são, hoje, objeto de normas específicas do direito internacional. A interdependência biológica ou a fraternidade religiosa de todos os seres humanos transmudam-se, assim, em autêntica solidariedade jurídica, que cria direitos e obrigações. COMPARATO, Fábio Konder. Ética: direito, moral e religião no mundo moderno. p. 583. 
PEREIRA NETO, Alexandre Nogueira. Neoliberalismo e Solidariedade: breves apontamentos da Teoria Crítica do Direito. Revista Eletrônica Direito e Política, Programa de Pós-Graduação Stricto Sensu em Ciência Jurídica da UNIVALI, Itajaí, v.14, n.2, $2^{\circ}$ quadrimestre de 2019. Disponível em: www.univali.br/direitoepolitica - ISSN 1980-7791

no seio de uma mesma comunidade. Na perspectiva da igualdade e da liberdade, cada qual reivindica o que lhe é próprio. No plano da solidariedade, todos são convocados a defender o que Ihes é comum. Quanto à segurança, ela só pode realizar-se em sua plenitude quando cada qual zela pelo bem de todos e a sociedade pelo bem de cada um dos seus membros. ${ }^{34}$

A política econômica neoliberal, que cria uma arena de combate no âmbito social, descaracteriza a natureza do Homem, ${ }^{35}$ uma vez que "o princípio da solidariedade está sustentado na natureza do Homem, pois ele constitui sua natureza, com isso sua identidade. Ela existirá enquanto existir o Homem, este é o fundamento da tese do ser humano como ser social". ${ }^{36}$

A solidariedade está inserida na constituição do ser humano, uma vez que ela é fundamental para a sua própria existência. Sem a presença da solidariedade, os indivíduos, que habitam um determinado terreno social, tornar-se-ão, cada vez mais, solitários. E é exatamente esse o comportamento que essa economia vislumbra, haja vista que o sentimento solidário é manipulado pelos padrões neoliberais. O total isolamento - sem, portanto, diálogo - é necessário para que os donos do poder possam determinar os rumos do País sem a interferência da sociedade.

Passe-se, agora, à análise da teoria crítica do direito, que, na perspectiva do autor, é um meio de transformação social, pois, a partir de políticas de Estado e, portanto do Direito, surge a expectativa de que inquietações sociais possam,

${ }^{34}$ COMPARATO, Fábio Konder. Ética: direito, moral e religião no mundo moderno. p. 581.

${ }^{35}$ A solidariedade não é exclusividade do Homem. "Muito pelo contrário, pode-se dizer que a biosfera forma naturalmente um sistema solidário, e que o rompimento desse sistema é sempre obra do homem. O próprio Darwin bem advertiu que a expressão struggle for Existence fora por ele usada em "sentido amplo e metafórico, incluindo a dependência de um ser em relação a outro, bem como incluindo (o que é mais importante) não apenas a vida do indivíduo, mas êxito em deixar descendentes. Os zoólogos já observavam que o processo de seleção natural deu mais vantagens biológicas aos grupos que cuidavam de seus membros não reprodutivos, do que àqueles que abandonavam ou matavam os anciãos, pois a capacidade de reprodução global dos grupos altruístas é, assim, singularmente reforçada." COMPARATO, Fábio Konder. Ética: direito, moral e religião no mundo moderno. p. 582.

36 MORAIS, José Luiz Bolzan de; MASSAÚ, Guilherme Camargo. A solidariedade como elemento constitutivo da res pública. Pensar, Fortaleza, v. 16, n. 1, p. 166, jan./jun. 2011. 
PEREIRA NETO, Alexandre Nogueira. Neoliberalismo e Solidariedade: breves apontamentos da Teoria Crítica do Direito. Revista Eletrônica Direito e Política, Programa de Pós-Graduação Stricto Sensu em Ciência Jurídica da UNIVALI, Itajaí, v.14, n.2, 20 quadrimestre de 2019. Disponível em: www.univali.br/direitoepolitica - ISSN 1980-7791

definitivamente, ser implantadas e, assim, proporcionar, sobretudo, a efetivação dos objetivos fundamentais da República e, especificamente, a solidariedade.

\section{TEORIA CRÍTICA DO DIREITO}

Antes de fazer o diálogo entre a política econômica neoliberal e o fundamento da solidariedade, importante trazer o significado de crítica. Crítica, portanto, é a "análise avaliativa de alguma coisa; ação de julgar ou de criticar". ${ }^{37}$ Será utilizada, neste trabalho, a teoria crítica do direito ${ }^{38}$ diante da necessidade de uma análise avaliativa entre os parâmetros que norteiam a estrutura econômica, política e jurídica do País - neoliberalismo e solidariedade.

Nesse sentido, a teoria crítica do direito ${ }^{39}$ é impreterível, inclusive nos dias atuais, para, a partir dela, contrapor os preceitos estanques e, em princípio, inquestionáveis que são desempenhados na vida contemporânea. Assim, essa teoria servirá de suporte para análise de quais interesses a política neoliberal atende e seus efeitos, na medida em que, conforme traduz Wolkmer:

[...] a formulação teórico-prática que se revela sob a forma do exercício reflexivo capaz de questionar e de romper com o que está disciplinarmente ordenado e oficialmente consagrado (no conhecimento, no discurso e no comportamento) em dada formação social e a possibilidade de conceber e operacionalizar outras formas diferenciadas, não repressivas e emancipadoras, de prática jurídica. ${ }^{40}$

37 HOUAISS, Antônio. Dicionário Houaiss da Língua Portuguesa. Rio de Janeiro: Ed. Objetiva, 2009.

38 Os primórdios do movimento da crítica no Direito foram gestados no final dos anos 60 , através da influência sobre juristas europeus de ideias provindas do economicismo jurídico soviético (Stucka, Pashukanis), da releitura gramsciana da teoria marxista feita pelo grupo de Althusser, da teoria frankfurtiana e das teses arqueológicas de Foucault sobre o poder. WOLKMER, Antônio Carlos. Introdução ao pensamento jurídico crítico. 4 ed. São Paulo: Saraiva, 2002. p. 16.

39 A palavra crítica aqui é utilizada com o significado que lhe atribuiu Marx e não como o que lhe atribuiu Kant. Pertence, portanto, ao discurso político e não ao discurso epistemológico. Não se trata de, através da crítica do direito, submeter o direito a uma análise pormenorizada para estudálo cuidadosamente. Isto é necessário e prévio, mas a crítica pretende outra coisa. Em primeiro lugar, a crítica, em sua concepção marxiana, é um ato de rechaço, desde o ponto de vista ético, da organização social que utiliza este e não qualquer outro direito. CORREAS, Óscar. Crítica da ideologia jurídica: ensaio sócio-semiológico. Porto Alegre: Sérgio Antônio Fabris Editor, 1995.

40 WOLKMER, Antônio Carlos. Introdução ao pensamento jurídico crítico. p. 18. 
PEREIRA NETO, Alexandre Nogueira. Neoliberalismo e Solidariedade: breves apontamentos da Teoria Crítica do Direito. Revista Eletrônica Direito e Política, Programa de Pós-Graduação Stricto Sensu em Ciência Jurídica da UNIVALI, Itajaí, v.14, n.2, $2^{\circ}$ quadrimestre de 2019. Disponível em: www.univali.br/direitoepolitica - ISSN 1980-7791

Corroborando, nesse sentido, deve-se, portanto, "denunciar como as funções políticas e ideológicas das concepções normativistas do Direito e do Estado encontram-se apoiadas na falaciosa separação do Direito e da Política e na utópica ideia da primazia da lei como garantia dos indivíduos". ${ }^{41}$

A teoria crítica do direito ${ }^{42}$ serve de paradigma para criar horizontes de mudança do status quo em relação aos preocupantes efeitos da cultura neoliberal que vem sendo difundida cada vez com mais força nos programas de governos mundiais. Os projetos neoliberais hegemônicos, diante de sua atuação global, estão conquistando todas as arenas públicas e, com isso, decidindo de forma discricionária sobre assuntos de interesse popular com a finalidade de, exclusivamente, promover os seus pares.

Cria-se, destarte, um estado de exceção, que "é uma exigência do atual modelo de dominação neoliberal. É o meio pelo qual se neutraliza a prática democrática e se reconfiguram, de modo silencioso, os regimes políticos em escala universal".43

Essa proposta crítica do direito ajuda na reflexão das premissas estabelecidas e a partir de movimentos que possibilitam o rompimento dessas características estruturais impulsiona-se a transformação da sociedade no sentido de ser uma opção de um ambiente no qual as pessoas possam conviver, sobretudo, em solidariedade. Porém, não é o que ocorre, pois a sociedade neoliberal fomenta a concorrência entre os indivíduos, entre outros fatores, e não a troca.

De outra banda, conforme o paradigma atual que se apresenta, setores empresariais perceberam a excelente oportunidade de aumentar suas políticas privadas e aproximaram-se das gerências estatais e "essa participação acabou por se revelar altamente benéfica aos detentores de capital e dirigentes de empresas, pois o Estado passou a ser um grande financiador e um dos principais

\footnotetext{
${ }^{41}$ WARAT, Luis Alberto. A pureza do poder. Florianópolis: Ed. UFSC, 1983. p. 39.

42 O objetivo prático, portanto, da teoria crítica do direito é "movido por ideais de emancipação, buscando a subversão desse direito ou sua instrumentalização em um sentido alternativo ao que tradicionalmente Ihe tem sido dada". LLEDÓ, Juan A. Pérez. Teorías críticas del Derecho. Em: Garzón Valdéz, Ernesto et alii. El derecho y la justicia. Madrid: Consejo Superior de Investigaciones Científicas, Boletín Oficial del Estado e Editorial Trotta, 1996. p. 100.

${ }^{43}$ VALIM, Rafael. Estado de Exceção: a forma jurídica do neoliberalismo. p. 34.
} 
PEREIRA NETO, Alexandre Nogueira. Neoliberalismo e Solidariedade: breves apontamentos da Teoria Crítica do Direito. Revista Eletrônica Direito e Política, Programa de Pós-Graduação Stricto Sensu em Ciência Jurídica da UNIVALI, Itajaí, v.14, n.2, $2^{\circ}$ quadrimestre de 2019. Disponível em: www.univali.br/direitoepolitica - ISSN 1980-7791

consumidores, associando-se com muita frequência aos maiores e mais custosos empreendimentos". 44

Até porque:

[...] a lei sempre emana do Estado e permanece, em última análise, ligada à classe dominante, pois o Estado, como sistema de órgãos que regem a sociedade politicamente organizada, fica sob o controle daqueles que comandam o processo econômico, na qualidade de proprietário dos meios de produção. ${ }^{45}$

Portanto, "o neoliberalismo não é uma retirada do Estado da economia, mas um específico modo de presença do Estado na economia". ${ }^{46}$

Mascaro sintetiza de forma brilhante a aproximação que se deu entre o capitalismo e o Estado e seus impactos diante desse enlace na sociedade:

[...] a relação entre o capitalismo e o Estado se estabelece a partir de uma penetração do econômico no político, num processo de implicação recíproca; as duas regiões do todo social se erigem e se estruturam conjuntamente. Tanto a economia capitalista não existe sem uma forma política estatal correspondente quanto esta só pode existir nas condições de reprodução econômica capitalista. Tal manifestação dúplice, no entanto, é eivada de contradições. A relação entre economia e política, no capitalismo, não se estabelece e se reitera de modo automático, nem pode ser pensada como uma derivação lógica de todos os seus termos, tampouco se apresenta como portadora de funcionalidades necessárias. A articulação entre o nível econômico e o nível político das sociedades capitalistas apresenta variações, contradições, conflitos e rupturas. No capitalismo, as formas da sociabilidade se estruturam em relação de exploração, dominação, concorrência, antagonismo de indivíduos, grupos, classes e Estados. O conflito e a crise são marcas inexoráveis da reprodução do capital. ${ }^{47}$

Diante disso, "a legislação abrange, sempre, em maior ou menor grau, Direito e Antidireito: isto é, Direito propriamente dito, reto e correto, e negação do Direito,

\footnotetext{
44 DALLARI, Dalmo de Abreu. Elementos de teoria geral do estado. p. 284.

45 LYRA FILHO, Roberto. O que é direito. São Paulo: Nova Cultural, 1985. p. 8.

46 MASCARO, Alysson Leandro. Estado e forma política. São Paulo: Boitempo, 2013. p. 118.

47 MASCARO, Alysson Leandro. Estado e forma política. p. 111.
} 
PEREIRA NETO, Alexandre Nogueira. Neoliberalismo e Solidariedade: breves apontamentos da Teoria Crítica do Direito. Revista Eletrônica Direito e Política, Programa de Pós-Graduação Stricto Sensu em Ciência Jurídica da UNIVALI, Itajaí, v.14, n.2, 20 quadrimestre de 2019. Disponível em: www.univali.br/direitoepolitica - ISSN 1980-7791

entornado pelos interesses classísticos e caprichos continuístas do poder estabelecido". ${ }^{48}$

Importante destacar uma crítica ao modelo positivista, uma vez que estabelecida a ordem, por meio de leis emanadas pelo Estado neoliberal, ${ }^{49}$ o que resta à população são, na verdade, ínfimas observações do comando constitucional, pois o que se pretende, nesse modelo econômico, não é construir um ambiente socialsolidário adequado, assegurando, portanto, meios suficientes à subsistência humana, e sim priorizar intocáveis privilégios das elites financeiras e, ainda, precarizar os direitos sociais, flexibilizando-os, ${ }^{50}$ ou até retirando-os da legislação.

Diante das consequências sociais que são geradas pela política neoliberalizantes, resta evidente a dissonância que há, no sentido de convívio, entre ela e o objetivo fundamental da solidariedade constitucional. Nesse viés, conforme dispõe Mascaro:

[...] as crises do capitalismo não são excepcionais a esse modo de produção, mas sim suas características estruturais. Num regime de exploração, constituído de múltiplos agentes na produção e na troca, enraizado em desigualdades reais e em lutas de classes e grupos, permeado por formas sociais e instituições necessárias e relativamente estranhas ao interesse dos próprios agentes, as contradições são múltiplas, tanto no plano econômico quanto no plano político. O Estado tem papel fundamental na constituição das crises, na medida em que é forma necessária desse modelo de reprodução social. 51

Como assevera Aguiar, "é verdade que nosso direito é burguês, mas também é verdade que nosso direito apresenta fissuras e aberturas pelas quais se pode introduzir uma interpretação alternativa dentro dos parâmetros normais". ${ }^{52}$ Por isso, a teoria crítica do direito vem como "um instrumental teórico destinado a

\footnotetext{
48 LYRA FILHO, Roberto. O que é direito. p. 9.

49 A identificação entre Direito e lei pertence, aliás, ao repertório ideológico do Estado, pois na sua posição privilegiada ele desejaria convencer-nos de que cessaram as contradições, que o poder atende ao povo em geral e tudo o que vem dali é imaculadamente jurídico, não havendo Direito a procurar além ou ainda das leis. LYRA FILHO, Roberto. O que é direito. p. 9.

50 Eufemismo muito utilizado pelos governos neoliberais para retroceder importantes direitos consagrados.

51 MASCARO, Alysson Leandro. Estado e forma política. p. 125.

52 AGUIAR, Roberto A. R. de. Direito, poder e opressão. São Paulo: Alfa-Omega, 1984. p. 122.
} 
PEREIRA NETO, Alexandre Nogueira. Neoliberalismo e Solidariedade: breves apontamentos da Teoria Crítica do Direito. Revista Eletrônica Direito e Política, Programa de Pós-Graduação Stricto Sensu em Ciência Jurídica da UNIVALI, Itajaí, v.14, n.2, $2^{\circ}$ quadrimestre de 2019. Disponível em: www.univali.br/direitoepolitica - ISSN 1980-7791

profissionais que ambicionam colocar seu saber-atuação na perspectiva de uma sociedade radicalmente democrática". ${ }^{53}$

Ou seja, a teoria crítica do direito serve como um instrumento ideológico de transformação da conjuntura atual. A partir dessa teoria, deve-se desenvolver alternativas à política econômica neoliberal no sentido da transformação social na busca efetiva da solidariedade entre os indivíduos, pois essa corrente vai de encontro do estabelecido que "acentua a ideia de que o direito contemporâneo é vinculado à manutenção capitalista e dos valores políticos e econômicos do neoliberalismo". ${ }^{54}$

Portanto, é preciso refundar o Estado Democrático de Direito e, consequentemente, as políticas econômicas que são desenvolvidas no espaço brasileiro para que, a partir disso, sejam criados alicerces às interferências internacionais, motivadas pela economia neoliberal, no sentido de promover alternativas a essas práticas, com intuito de consolidar, de uma vez por todas, o objetivo fundamental da República, que é o da solidariedade. O Estado, portanto, adotando as práticas neoliberais e consolidando parcerias com grandes empresas, torna-se refém de suas imposições e, por isso, privilegia os interesses empresariais em detrimento dos anseios coletivos.

Nessa linha de raciocínio, é que aduz Harvey:

[...] en caso de conflicto, el Estado neoliberal típico tenderá a privilegiar un clima óptimo para las empresas frente a los derechos colectivos (y la calidad de vida) de la fuerza de trabajo o frente a la capacidad del medio ambiente para regenerarse. El segundo aspecto en el que se manifiesta la parcialidad emerge porque en caso de conflicto el Estado neoliberal favorece de manera invariable la integridad del sistema financiero y la solvencia de las instituciones financieras sobre el bienestar de la población o la calidad medioambiental. 55

53 CARVAlHo, Amilton Bueno de; CARVALHO, Salo. Aplicação da pena e garantismo. 2 ed. Porto Alegre: Lumen Juris, 1998. p. 50.

54 COSTA, Alexandre Araujo. Introdução ao Direito: uma perspectiva zetética das ciências jurídicas. Porto Alegre: Sergio Antonio Fabri, 2001. p. 296.

55 HARVEY, David. Breve historia del Neoliberalismo. España: Akal, 2015. p. 77-78. 
PEREIRA NETO, Alexandre Nogueira. Neoliberalismo e Solidariedade: breves apontamentos da Teoria Crítica do Direito. Revista Eletrônica Direito e Política, Programa de Pós-Graduação Stricto Sensu em Ciência Jurídica da UNIVALI, Itajaí, v.14, n.2, 20 quadrimestre de 2019. Disponível em: www.univali.br/direitoepolitica - ISSN 1980-7791

Tem-se que criar barreiras para impedir, o máximo possível, os efeitos que a política econômica neoliberal propaga. Essas decisões econômicas resultaram em graves crises financeiras mundiais e, muito embora esses fatores tenham sido devastadores para muitas sociedades, essa receita ainda continua sendo replicada. ${ }^{56}$

É o que sinaliza Dardot e Laval:

Como é que, apesar das consequências catastróficas a que nos conduziram as políticas neoliberais, essas políticas estão cada vez mais ativas, a ponto de afundar os Estados e as sociedades em crises políticas e retrocessos sociais cada vez mais graves? Como é que, há mais de trinta anos, essas mesmas políticas vêm se desenvolvendo e se aprofundando, sem encontrar resistências suficientemente substanciais para colocá-las em xeque? ${ }^{57}$

Em razão disso, premente é o desenvolvimento de mecanismos políticos, jurídicos e filosóficos para que o objetivo fundamental da solidariedade ganhe efetividade e que não seja apenas um comando constitucional prescritivo.

Diante dessa proposta, o que se deve buscar é:

[...] o sentido da política como veículo de assimilação e resolução coletiva da conflitividade social, em que o outro é visto como um semelhante e não como um inimigo. Assim, deve-se substituir a lógica da guerra, própria da necropolítica neoliberal, pela lógica da solidariedade. ${ }^{58}$

Já no sentido jurídico, deve-se atentar "descolonizar o conhecimento jurídico [...] em que a descrição do direito positivo seja acompanhada da denúncia dos desvios na aplicação normativa e da proposição de estratégias de colmatação das lacunas que impedem a plena realização da Constituição". ${ }^{59} \mathrm{E}$, no plano filosófico, deve-se

56 E "isso implica, inelutavelmente, uma radical transformação da relação hoje existente entre economia e política. Aquela deve ser subalterna a esta, ou, em outras palavras, a economia deve servir às pessoas e não o contrário. Daí emergirão as condições para o enfretamento da criminosa desigualdade social que, em rigor, inviabiliza qualquer projeto de sociedade democrática. VALIM, Rafael. Estado de Exceção: a forma jurídica do neoliberalismo. p. 55.

57 DARDOT, Pierre; LAVAL, Christian. A nova razão do mundo: ensaios sobre a sociedade neoliberal. p. 15.

58 VALIM, Rafael. Estado de Exceção: a forma jurídica do neoliberalismo. p. 54.

59 VALIM, Rafael. Estado de Exceção: a forma jurídica do neoliberalismo. p. 55. 
PEREIRA NETO, Alexandre Nogueira. Neoliberalismo e Solidariedade: breves apontamentos da Teoria Crítica do Direito. Revista Eletrônica Direito e Política, Programa de Pós-Graduação Stricto Sensu em Ciência Jurídica da UNIVALI, Itajaí, v.14, n.2, $2^{\circ}$ quadrimestre de 2019. Disponível em: www.univali.br/direitoepolitica - ISSN 1980-7791

atentar para que se produzam elementos de discussão reflexiva no sentido de incentivar e demonstrar o porquê da importância da participação efetiva da sociedade em demandas sociais para a transformação social-solidária e para que valores imperativos neoliberais sejam afastados do plano econômico e, assim, criar uma consciência coletiva plena que objetiva a emancipação do todo.

Depreende-se dessa discussão, que a teoria crítica do direito ainda é um elemento de resistência. Nesse caso, à economia neoliberal, tendo em vista que, a partir dela, viabilizam-se elementos políticos, de viés progressista, para desfazer paradigmas hegemônicos e buscar, incessantemente, mecanismos alternativos, com intuito de afastar o neoliberalismo e seus efeitos, que causam, em qualquer ambiente social que é promovido, e consolidar, enfim, a solidariedade republicana.

\section{CONSIDERAÇÕES FINAIS}

A solidariedade é uma conquista de um Estado Democrático de Direito, e, portanto, o Estado deve, por meio de suas atribuições e ações, sobretudo, positivas, efetivar esse objetivo fundamental previsto na Constituição da República Federativa do Brasil de 1988 para justificar, inclusive, sua qualidade democrática.

Contudo, em meio ao imbróglio da efetividade da solidariedade, é cediço que as complexidades e as contradições que permeiam a sociedade contemporânea, impulsionadas, sobretudo, pela política econômica neoliberalizante dificultem, ainda mais, o convívio solidário entre povos e nações. Essa política, que promove a competição entre os indivíduos, a miséria, a fome, a desigualdade social, a concentração de renda, viabiliza a sensação de que é cada um por si, tornando, portanto, o espaço público em uma verdadeira arena de confronto e rivalidade.

O objetivo fundamental da solidariedade, no sentido desenvolvido neste trabalho, se dá pela ideia da troca, do diálogo, do auxílio, da percepção do outro não pelo viés competitivo e, assim, tornando-o um inimigo que merece ser superado, e sim pelo prisma da responsabilidade mútua entre os pares que convivem no mesmo espaço social. Deve haver, portanto, um diálogo coletivo para concretizar o controle social nas demandas político-econômicas para que, a partir dessas 
PEREIRA NETO, Alexandre Nogueira. Neoliberalismo e Solidariedade: breves apontamentos da Teoria Crítica do Direito. Revista Eletrônica Direito e Política, Programa de Pós-Graduação Stricto Sensu em Ciência Jurídica da UNIVALI, Itajaí, v.14, n.2, $2^{\circ}$ quadrimestre de 2019. Disponível em: www.univali.br/direitoepolitica - ISSN 1980-7791

intervenções, promova-se o desenvolvimento e o aperfeiçoamento dos direitos humanos e sociais e viabilize a solidariedade.

Propõe-se que a transformação social pode ser guiada pelos critérios desenvolvidos pela teoria crítica do direito que é, justamente, a efetivação de uma contra-hegemonia no sentido de criar, por meio de critérios jurídicos, políticos e filosóficos, mecanismos alternativos à sociedade incentivada pelos paradigmas neoliberalizantes. Mas a pergunta que se coloca é: o Estado será capaz de disciplinar o capital internacional em defesa dos direitos sociais e da solidariedade, tendo em vista o fator de a globalização influenciar nesses aspectos em pleno século XXI? Tal resposta é o que devemos perseguir, e tê-la em nosso horizonte, para que, parafraseando Eduardo Galeano, passo a passo, possamos, embora o horizonte sempre se distancie, continuar caminhando.

Assim, diante de todos os fatores elencados, resta evidente a impossibilidade de convívio entre o neoliberalismo e a solidariedade no plano político-econômico do Brasil, quiçá mundial, quando praticados em uma mesma área coletiva. Aquele objetiva o individualismo, o desenvolvimento de interesses de um conjunto seleto; este objetiva o convívio, a socialização de demandas públicas. Ou seja, esses elementos são antagônicos e não conversam entre si, embaraçando o seu contato harmonioso.

\section{REFERÊNCIA DAS FONTES CITADAS}

AGUIAR, Roberto A. R. de. Direito, poder e opressão. São Paulo: Alfa-Omega, 1984.

BRASIL. Constituição da República Federativa do Brasil de 5 de outubro de 1988.

<http://www.planalto.gov.br/ccivil_03/constituicao/constituicaocompilado.htm>. Acesso em: 31 out. 2018.

CARVAlHo, Amilton Bueno de; CARVALHO, Salo. Aplicação da pena e garantismo. 2 ed. Porto Alegre: Lumen Juris, 1998.

CHOMSKY, Noam. O lucro ou as pessoas. Seven Stories Press: NY, 1999.

COMPARATO, Fábio Konder. Ética: direito, moral e religião no mundo 
PEREIRA NETO, Alexandre Nogueira. Neoliberalismo e Solidariedade: breves apontamentos da Teoria Crítica do Direito. Revista Eletrônica Direito e Política, Programa de Pós-Graduação Stricto Sensu em Ciência Jurídica da UNIVALI, Itajaí, v.14, n.2, $2^{\circ}$ quadrimestre de 2019. Disponível em: www.univali.br/direitoepolitica - ISSN 1980-7791

moderno. 3 ed. São Paulo: Companhia das Letras, 2016.

CORREAS, Óscar. Crítica da ideologia jurídica: ensaio sócio-semiológico. Porto Alegre: Sérgio Antônio Fabris Editor, 1995.

COSTA, Alexandre Araujo. Introdução ao Direito: uma perspectiva zetética das ciências jurídicas. Porto Alegre: Sergio Antonio Fabri, 2001.

DALLARI, Dalmo de Abreu. Elementos de teoria geral do estado. 27 ed. São Paulo: Saraiva, 2007.

DARDOT, Pierre; LAVAL, Christian. A nova razão do mundo: ensaios sobre a sociedade neoliberal. 1 ed. São Paulo: Boitempo, 2016.

HARVEY, David. Breve historia del Neoliberalismo. España: Akal, 2015.

HOUAISS, Antônio. Dicionário Houaiss da Língua Portuguesa. Rio de Janeiro: Ed. Objetiva, 2009.

LLEDÓ, Juan A. Pérez. Teorías críticas del Derecho. Em: Garzón Valdéz, Ernesto et alii. El derecho y la justicia. Madrid: Consejo Superior de Investigaciones Científicas, Boletín Oficial del Estado e Editorial Trotta, 1996.

LYRA FILHO, Roberto. O que é direito. São Paulo: Nova Cultural, 1985.

MASCARO, Alysson Leandro. Estado e forma política. São Paulo: Boitempo, 2013.

MORAIS, José Luiz Bolzan de; MASSAÚ, Guilherme Camargo. A solidariedade como elemento constitutivo da res pública. Pensar, Fortaleza, v. 16, n. 1, p. 151-177, jan./jun. 2011.

VALIM, Rafael. Estado de Exceção: a forma jurídica do neoliberalismo. São Paulo: Contracorrente, 2017.

WARAT, Luis Alberto. A pureza do poder. Florianópolis: Ed. UFSC, 1983.

WOLKMER, Antônio Carlos. Introdução ao pensamento jurídico crítico. 4 ed. São Paulo: Saraiva, 2002.

RECEBIDO EM: 31/10/2018

APROVADO EM: 15/04/2019 